\title{
Level of agreement between 2002 American- European Consensus Group and 2012 American College of Rheumatology classification criteria for Sjögren's syndrome and reasons for discrepancies
}

\author{
Divi Cornec ${ }^{1,2}$, Alain Saraux ${ }^{1,2}$, Béatrice Cochener ${ }^{3}$, Jacques-Olivier Pers ${ }^{2,4}$, Sandrine Jousse-Joulin ${ }^{1,2}$, \\ Yves Renaudineau ${ }^{2,5}$, Thierry Marhadour ${ }^{1}$ and Valérie Devauchelle-Pensec ${ }^{1,2,6^{*}}$
}

\begin{abstract}
Introduction: The aims of this study were to assess agreement between the currently used 2002 AmericanEuropean Consensus Group (AECG) classification criteria and the new 2012 American College of Rheumatology (ACR) criteria for Sjögren's syndrome (SS) and to identify potential sources of disagreement.

Methods: We studied 105 patients between 2006 and 2013 from the Brittany cohort of patients with suspected SS. AECG criteria were applied using only Schimer's test and unstimulated whole salivary flow (UWSF) to assess objective ocular and oral involvement, since these are the tests most physicians use in clinical practice. Agreement between the two sets of criteria was assessed using Cohen's k coefficient.

Results: Of those studied, 42 patients fulfilled AECG and 35 ACR criteria. Agreement between the two sets was moderate $(k=0.53)$. Patients fulfilling ACR but not AECG criteria $(n=8)$ were significantly younger and had shorter symptom durations, but only three of them had SS in the opinion of the evaluating physician. Xerostomia and xerophthalmia (AECG set only) did not discriminate between patients with and without SS. The use of UWSF in the AECG but not the ACR criteria explained part of the disagreement. The serological item in the ACR set (positive rheumatoid factor and antinuclear antibody $\geq 1: 320$ or anti-SSA/SSB positivity) did not result in classification differences compared to anti-SSA/SSB antibody alone (AECG set). Agreement between ocular staining score $\geq 3$ (ACR set) and Schirmer's test $\leq 5 \mathrm{~mm} / 5$ min (AECG set) was very low $(K=0.14)$.
\end{abstract}

Conclusions: Agreement was only moderate between ACR and AECG criteria, suggesting these two sets would not select comparable patient populations. An international consensus about which classification criteria should be used in clinical studies is needed.

\section{Introduction}

The classification criteria for Sjögren's syndrome (SS) issued in 2002 by the American-European Consensus Group (AECG) have been widely used in clinical studies over the last decade [1]. In 2012, the Sjögren's International Collaborative Clinical Alliance issued new classification criteria, which have been endorsed by the American College of

\footnotetext{
* Correspondence: valerie.devauchelle-pensec@chu-brest.fr

'CedexService de Rhumatologie, CHRU Brest, Hôpital de la Cavale Blanche, Boulevard Tanguy Prigent, 29609 Brest Cedex, France

2EA 2216 Immunologie et Pathologie, SFR ScinBios, Labex 'Immunotherapy, Graft, Oncology', Faculté de médecine de Brest, avenue Camille Desmoulins, 29200 Brest, France

Full list of author information is available at the end of the article
}

Rheumatology (ACR) [2]. These new criteria are intended for use in patients referred to specialists because of signs or symptoms suggesting SS. They were developed by asking experts in rheumatology, ophthalmology and oral medicine to select the items they felt were most relevant.

The new criteria differ substantially from the 2002 AECG criteria in three ways: they include no subjective ocular and oral symptoms and no functional or morphological tests for the salivary glands; they use a new ocular staining score (OSS) [3] as the only criterion for ocular involvement; and they allow the use of an antinuclear antibody (ANA) titer $\geq 1: 320$ plus rheumatoid factor (RF) 
positivity as an alternative to anti-SSA/SSB antibody positivity for the assessment of systemic autoimmunity.

Here, our objectives were to evaluate agreement between the two criteria sets and to identify sources of disagreement.

\section{Methods \\ Study population}

We studied the single-centre Brittany cohort of patients with suspected SS included between November 2006 and March 2013 in Brittany, France. The inclusion criteria are described elsewhere [4]. Briefly, patients were addressed to our consultation by their family physician, rheumatologist, internist, dentist or ophthalmologist if SS was suspected due to sicca complaints, major salivary gland swelling, suggestive extraglandular features or suggestive autoantibodies. Written consent was obtained from all participants, and the study was approved by the local ethics committee (Brest University Hospital).

This study included 105 patients of the cohort who had all the tests available to apply both ACR and AECG criteria, including 99 (94.3\%) women. Mean age was $57.2 \pm 13.7$ years and mean symptom duration was $6.7 \pm$ 6.1 years.

\section{Clinical evaluation and laboratory tests}

Schirmer's test was considered abnormal if $\leq 5 \mathrm{~mm} / 5 \mathrm{mi}$ nute and the unstimulated whole salivary flow if $<0.1 \mathrm{ml} /$ minute. ANAs were assessed on HEp- 2 cells and anti-SSA and anti-SSB antibodies using commercial enzyme-linked immunosorbent assays, and RF (IgM and IgA isotypes) using in-house enzyme-linked immunosorbent assays. Minor labial salivary gland biopsy was performed in all patients and graded according to the semi-quantitative score of Chisholm and Mason [5]. Salivary gland biopsy grades 3 and 4 indicating focus scores $\geq 1 / 4 \mathrm{~mm}^{2}$ were considered abnormal.

\section{Ophthalmologic evaluation}

All patients underwent a slit-lamp examination by an ophthalmologist experienced in dry-eye diseases. The corneal fluorescein pattern was graded from 0 (no punctate epithelial erosions) to 3 (severe keratitis). A drop of lissamine green dye was then instilled into the inferior conjunctival fornix of each eye, the patient was asked to blink several times, and the nasal and temporal bulbar conjunctivae were then immediately graded semi-quantitatively from 0 (no staining) to 3 (diffuse dot staining or confluent staining).

The Sjögren's International Collaborative Clinical Alliance OSS [3] was published during the inclusion period for our cohort. We retrospectively computed the OSS of both eyes as the 0 to 12 sum of the 0 to 3 lissamine green scores for the nasal and temporal conjunctiva (range, 0 to
6) plus the 0 to 3 fluorescein score for each cornea multiplied by 2 (because the specific patterns of corneal fluorescein staining giving additional points in the OSS (central staining, filaments or confluent staining) were not described in our protocol). OSS $\geq 3$ in at least one eye was considered abnormal.

\section{Case ascertainment}

Table 1 presents the rules for classification using the AECG and ACR criteria sets. AECG criteria were applied using only Schirmer's test and unstimulated whole salivary flow, which are the tests we use in clinical practice to assess objective ocular and salivary gland involvement.

The evaluating physician was also asked to define the most probable diagnosis in his opinion for each patient, without referring to specific classification criteria. All cases were reviewed by a panel of three experts (VD-P, AS and SJ-J) to reach consensus. The most probable diagnoses in the opinion of the experts were SS in 47 (44.8\%) patients, idiopathic sicca syndrome in $37(35.2 \%)$ patients, other connective tissue diseases in $11(10.5 \%)$ patients and druginduced sicca syndrome in 10 (9.5\%) patients.

This clinical definition of SS cases was not used as a gold standard to compare the diagnostic performance of AECG criteria and ACR criteria in terms of sensitivity and specificity, since the physician most probably used, even subconsciously, current validated classification criteria (that is, AECG criteria) to perform his diagnosis, leading to circular reasoning that would have overestimated AECG performance to the detriment of ACR criteria.

\section{Statistical analysis}

Statistical tests were performed using the Statistical Package for the Social Sciences (SPSS 18.0, 2009; SPSS Inc., Chicago, IL, USA). Quantitative variables were described as mean \pm standard deviation and qualitative variables as number (\%). Agreement between classification criteria sets and between criteria was evaluated using Cohen's kappa coefficient (к). To compare patient groups, we used the Mann-Whitney test, Fisher's exact test or the chi-square test as appropriate.

\section{Results}

\section{Classification criteria}

Of the 105 patients, 42 (40.0\%) fulfilled the AECG criteria and 35 (33.3\%) fulfilled the ACR criteria (Table 2). Agreement between the two criteria sets was moderate $(\kappa=0.53)$. Patients fulfilling only the ACR criteria were significantly younger and had shorter symptom durations than did patients fulfilling the AECG criteria (mean age, $46.6 \pm 15.8$ vs. $60.0 \pm 11.4$ years; and mean symptom duration, $2.9 \pm 2.4$ vs. $7.7 \pm 6.8$ years; $P<0.001$ for both comparisons). 
Table 1 Pragmatic AECG [1] and ACR [2] classification criteria for Sjögren's syndrome

\begin{tabular}{|c|c|c|}
\hline & Pragmatic 2002 AECG criteria & 2012 ACR criteria \\
\hline \multirow[t]{6}{*}{ Items } & 1. Ocular dryness symptoms & $\begin{array}{l}\text { 1. Positive anti-SSA or anti-SSB antibodies or } \\
\text { positive rheumatoid factor plus ANA } \geq 1: 320\end{array}$ \\
\hline & 2. Oral dryness symptoms & $\begin{array}{l}\text { 2. Focus score } \geq 1 \text { focus } / 4 \mathrm{~mm}^{2} \text { on minor } \\
\text { salivary gland biopsy }\end{array}$ \\
\hline & 3. Ocular signs: Schirmer's test $\leq 5 \mathrm{~mm} / 5$ minutes & $\begin{array}{l}\text { 3. Keratoconjunctivitis sicca with ocular } \\
\text { staining score } \geq 3\end{array}$ \\
\hline & 4. Focus score $\geq 1$ focus $/ 4 \mathrm{~mm}^{2}$ on minor salivary gland biopsy & \\
\hline & 5. Salivary gland involvement: unstimulated whole salivary flow $\leq 0.1 \mathrm{ml} /$ minute & \\
\hline & 6. Positive anti-SSA or anti-SSB antibodies & \\
\hline $\begin{array}{l}\text { Rules for } \\
\text { classification }\end{array}$ & $\begin{array}{l}\text { Presence of any four of the six items with at least item } 4 \text { or } 6 \text {, or presence of any three } \\
\text { of the four objective items (items } 3,4,5 \text { and } 6 \text { ) }\end{array}$ & $\begin{array}{l}\text { In a patient with suspected Sjögren's } \\
\text { syndrome, any two of the three items }\end{array}$ \\
\hline
\end{tabular}

Description of the patients with discordant classification Table 3 details the features of the eight patients fulfilling ACR criteria but not AECG criteria and of the 15 patients fulfilling AECG criteria but not ACR criteria. All patients fulfilling only AECG criteria had sicca complaints, either abnormal unstimulated whole salivary flow or Schirmer's test, and either anti-SSA/SSB antibodies or abnormal salivary gland biopsy. Five of them had extraglandular involvement, and all of them had SS in the opinion of the evaluating physician.

Among the eight patients fulfilling only ACR criteria, none of them had abnormal unstimulated whole salivary flow or Schirmer's test, but seven had abnormal salivary gland biopsy. Only three of them had SS according to the physician's opinion, and other more likely diagnoses were rheumatoid arthritis $(n=2)$, systemic lupus erythematosus $(n=1)$, undifferentiated connective tissue disease $(n=1)$ and idiopathic sicca syndrome $(n=1)$.

\section{Subjective sicca complaints (AECG set only)}

The subjective sicca symptoms (xerophthalmia and xerostomia) were noted in nearly all of the patients (respectively in $92.4 \%$ and $94.3 \%$ ), suggesting no ability of these symptoms to discriminate between patients with

Table 2 Characteristics of patients meeting ACR and/or AECG criteria for Sjögren's syndrome

\begin{tabular}{|c|c|c|c|c|}
\hline & & & ling & \\
\hline & $\begin{array}{c}\text { Both sets } \\
(n=27)\end{array}$ & $\begin{array}{l}\text { ACR set only } \\
\qquad(n=8)\end{array}$ & $\begin{array}{l}\text { AECG set only } \\
\quad(n=15)\end{array}$ & $\begin{array}{c}\text { Neither set } \\
(n=55)\end{array}$ \\
\hline Age (years) & $60.7 \pm 11.7$ & $46.6 \pm 15.8$ & $59.3 \pm 11.1$ & $56.4 \pm 14.5$ \\
\hline Symptom duration (years) & $9.5 \pm 7.4$ & $2.9 \pm 2.4$ & $4.7 \pm 4.3$ & $6.4 \pm 5.7$ \\
\hline Female & $25(92.6)$ & $8(100)$ & $14(93.3)$ & $52(94.5)$ \\
\hline Xerophthalmia & $26(96.3)$ & $6(75.0)$ & $14(93.3)$ & $50(90.9)$ \\
\hline Xerostomia & $27(100)$ & $6(75.0)$ & $15(100)$ & $51(92.7)$ \\
\hline Salivary flow $\leq 0.1 \mathrm{ml} /$ minute & $18(66.7)$ & $0(0)$ & $10(66.7)$ & $16(29.1)$ \\
\hline Schirmer's test $\leq 5 \mathrm{~mm} / 5$ minutes & $22(81.5)$ & $1(12.5)$ & $12(80.0)$ & $13(23.6)$ \\
\hline OSS $\geq 3$ & $24(88.9)$ & $6(75.0)$ & $0(0)$ & $19(34.5)$ \\
\hline Anti-SSA or anti-SSB positivity & $18(66.7)$ & $4(50.0)$ & $4(26.7)$ & $1(1.8)$ \\
\hline ANA $\geq 1: 320$ & $25(92.6)$ & $5(62.5)$ & $8(53.3)$ & $18(32.7)$ \\
\hline RF positivity & $14(51.9)$ & $4(50.0)$ & $1(6.7)$ & $6(10.9)$ \\
\hline Anti-SSA/SSB or RF plus ANA $\geq 1: 320$ & $21(77.8)$ & $4(50.0)$ & $4(26.7)$ & $1(1.8)$ \\
\hline Focus score $\geq 1$ & $24(88.9)$ & $7(87.5)$ & $11(73.3)$ & $6(10.9)$ \\
\hline
\end{tabular}

Data presented as mean \pm standard deviation or number (\%). Xerophthalmia and xerostomia referred to subjective complaints from the patients. ACR, American College of Rheumatology; AECG, American-European Consensus Group; OSS, ocular staining score; ANA, antinuclear antibody; RF, rheumatoid factor. 
Table 3 Description of the patients fulfilling only ACR criteria or only AECG criteria

\begin{tabular}{|c|c|c|c|c|c|c|c|c|c|c|c|c|c|c|c|c|c|c|c|c|}
\hline Patient & Sex & $\begin{array}{c}\text { Age } \\
\text { (years) }\end{array}$ & $\begin{array}{c}\text { Duration } \\
\text { (years) }^{\mathrm{a}}\end{array}$ & Eye $^{b}$ & Mouth $^{c}$ & Arthritis $^{d}$ & Lung $^{e}$ & Neuro $^{f}$ & Parotid $^{\mathrm{g}}$ & UWSF $^{\mathrm{h}}$ & Schirmer & OSS $^{\mathrm{j}}$ & Chisholm $^{k}$ & ANA & $\begin{array}{l}\text { Anti- } \\
\text { SSA' }\end{array}$ & $\begin{array}{l}\text { Anti- } \\
\text { SSB' }\end{array}$ & $\begin{array}{c}\mathrm{RF}(n< \\
0.2)\end{array}$ & $\begin{array}{c}\text { ACPA }(n \\
<20)\end{array}$ & $\begin{array}{c}\mathrm{IgG} \\
(\mathrm{mg} / \mathrm{l})\end{array}$ & Clinical $^{\mathrm{m}}$ \\
\hline \multicolumn{21}{|c|}{ Detailed characteristics of the eight patients fulfilling only ACR criteria } \\
\hline 1 & $\mathrm{~F}$ & 25 & 0 & 1 & 0 & 0 & 0 & 0 & 0 & 0.35 & 8 & 3 & 1 & 160 & 146 & 46 & 0.14 & 9 & 9.2 & SS \\
\hline 2 & $F$ & 63 & 1 & 1 & 1 & 0 & 0 & 0 & 0 & 0.4 & 30 & 3 & 4 & 1,280 & 0 & 0 & 0 & 0 & 5.8 & SS \\
\hline 3 & $\mathrm{~F}$ & 34 & 1 & 1 & 0 & 1 & 0 & 0 & 0 & 0.2 & 20 & 4 & 4 & 1,280 & 174 & 0 & 0.5 & 250 & 16.2 & RA \\
\hline 4 & $\mathrm{~F}$ & 59 & 5 & 0 & 1 & 0 & 0 & 0 & 1 & 0.4 & 10 & 1 & 3 & 640 & 140 & 80 & 0.9 & 7 & 13.4 & SS \\
\hline 5 & $F$ & 61 & 5 & 1 & 1 & 0 & 0 & 0 & 0 & 0.5 & 8 & 3 & 3 & 0 & 0 & 0 & 0 & 0 & 12.1 & Sicca \\
\hline 6 & $F$ & 47 & 4 & 1 & 1 & 0 & 0 & 0 & 0 & 0.2 & 30 & 3 & 3 & 1,280 & 0 & 0 & 0 & 0 & 16.5 & UCTD \\
\hline 7 & $F$ & 57 & 1 & 1 & 1 & 1 & 0 & 1 & 0 & 0.5 & 30 & 4 & 4 & 160 & 0 & 0 & 0.52 & 250 & 12.7 & RA \\
\hline 8 & $\mathrm{~F}$ & 27 & 6 & 0 & 1 & 0 & 1 & 0 & 0 & 0.25 & 30 & 0 & 3 & 1,280 & 100 & 0 & 0.81 & 15 & 18.9 & SLE \\
\hline
\end{tabular}

Detailed characteristics of the 15 patients fulfilling only AECG criteria

\begin{tabular}{|c|c|c|c|c|c|c|c|c|c|c|c|c|c|c|c|c|c|c|c|c|}
\hline 1 & $\mathrm{~F}$ & 67 & 1 & 1 & 1 & 0 & 0 & 0 & 0 & 0.005 & 5 & 2 & 3 & 160 & 0 & 0 & 0 & 0 & 11.7 & SS \\
\hline 2 & $\mathrm{~F}$ & 45 & 1 & 1 & 1 & 0 & 0 & 0 & 0 & 0.001 & 5 & 2 & 2 & 640 & 154 & 0 & 0.05 & 0 & 13 & SS \\
\hline 3 & $F$ & 75 & 0 & 1 & 1 & 0 & 0 & 0 & 0 & 0.2 & 0 & 2 & 3 & 0 & 0 & 0 & 0.34 & 0 & 9.3 & SS \\
\hline 4 & $F$ & 56 & 1 & 1 & 1 & 0 & 0 & 0 & 0 & 0.005 & 25 & 2 & 2 & 1,280 & 24 & 152 & 0 & 0 & 9.9 & SS \\
\hline 5 & F & 50 & 13 & 1 & 1 & 0 & 0 & 1 & 1 & 0.1 & 20 & 0 & 4 & 160 & 0 & 0 & 0 & 0 & 9.1 & SS \\
\hline 6 & $F$ & 69 & 6 & 1 & 1 & 0 & 0 & 0 & 0 & 0.25 & 5 & 1 & 4 & 1,280 & 0 & 0 & 0 & 0 & 10.3 & SS \\
\hline 7 & $F$ & 66 & 1 & 1 & 1 & 1 & 0 & 0 & 0 & 0.486 & 5 & 2 & 3 & 320 & 0 & 0 & 0 & 0 & 7 & SS \\
\hline 8 & $F$ & 55 & 7 & 1 & 1 & 0 & 1 & 0 & 0 & 0.02 & 15 & 2 & 4 & 160 & 0 & 0 & 0 & 0 & 7.1 & SS \\
\hline 9 & $F$ & 43 & 3 & 1 & 1 & 0 & 0 & 0 & 0 & 0.15 & 5 & 1 & 1 & 640 & 85 & 0 & 0 & 0 & 12.6 & SS \\
\hline 10 & $F$ & 78 & 10 & 1 & 1 & 0 & 0 & 0 & 0 & 0.05 & 7 & 2 & 3 & 160 & 0 & 0 & 0 & 0 & 9.7 & SS \\
\hline 11 & M & 64 & 2 & 1 & 1 & 0 & 1 & 0 & 0 & 0.2 & 0 & 0 & 4 & 320 & 0 & 0 & 0 & 28 & 22.6 & SS \\
\hline 12 & $F$ & 60 & 8 & 1 & 1 & 0 & 0 & 1 & 1 & 0.05 & 5 & 2 & 3 & 640 & 9 & 32 & 0 & 72 & 8.43 & SS \\
\hline 13 & $F$ & 58 & 2 & 1 & 1 & 0 & 0 & 0 & 0 & 0.04 & 4 & 0 & 3 & 0 & 0 & 0 & 0 & 0 & 8.33 & SS \\
\hline 14 & $F$ & 43 & 10 & 0 & 1 & 0 & 0 & 0 & 0 & 0.06 & 0 & 1 & 2 & 320 & 40 & 0 & 0 & 0 & 10 & SS \\
\hline 15 & $F$ & 50 & 1 & 1 & 1 & 0 & 0 & 0 & 0 & 0.05 & 15 & 1 & 3 & 0 & 0 & 0 & 0 & 0 & 9.7 & SS \\
\hline
\end{tabular}

ACPA, anti-citrullinated peptide antibodies; ACR, American College of Rheumatology; AECG, American-European Consensus Group; ANA, antinuclear antibody; F, female; IgG, serum level of immunoglobulin G; M, male; OSS, ocular staining score; SS, Sjögren's syndrome. RA, rheumatoid arthritis; RF, rheumatoid factor; sicca, idiopathic sicca syndrome; SLE, systemic lupus erythematosus; UCTD, undifferentiated connective tissue disease; UWSF, unstimulated whole salivary flow. ${ }^{a}$ Duration of the symptoms. ${ }^{b}$ Xerophthalmia $\left(0\right.$, absent; 1 , present). ${ }^{C}$ Xerostomia $\left(0\right.$, absent; 1 , present). ${ }^{d}$ Presence of swollen and tender joints on the day of examination. eIncludes the presence of chronic dry cough or computed tomography-proven interstitial lung disease. ${ }^{\mathrm{f} P a t i e n t}$ with objective peripheral neuropathy. ${ }^{\mathrm{P} P r e s e n c e}$ or history of parotidomegaly. ${ }^{\mathrm{h}} \mathrm{Abnormal}$ if $\leq 0.1 \mathrm{ml} / \mathrm{minute}$.

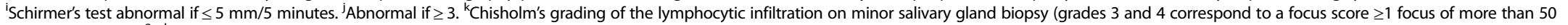
lymphocytes $\left./ 4 \mathrm{~mm}^{2}\right)$. Anti-SSA and anti-SSB antibodies $(n<40)$. "Diagnosis made by the physician, without reference to specific classification criteria. 
and without SS in this population. The proportions of patients with xerophthalmia or xerostomia were not significantly different in the group fulfilling both criteria sets and in the group fulfilling neither criteria set $(P=$ 0.35 and $P=0.2$, respectively).

\section{Functional salivary-gland assessment (AECG set only)}

Salivary flow was decreased in $66.7 \%$ of patients fulfilling both criteria sets and in $29.4 \%$ of those fulfilling neither criteria set $(P=0.001)$. No patient fulfilling only the ACR set had a decrease in salivary flow.

\section{Serological criterion}

Only three patients had positive RF plus ANA $\geq 1: 320$ but negative anti-SSA antibodies; that is, met the ACR serological criterion but not the AECG serological criterion. These three patients fulfilled the AECG criteria; they also fulfilled the ACR criteria even without taking RF and ANA into account, since they all had abnormal OSS and focus score results.

\section{Ophthalmological criterion}

Agreement between the OSS (ACR set) and Schirmer's test (AECG set) was very low $(\kappa=0.14)$. Agreement with the salivary gland biopsy was lower for the OSS than for Schirmer's test ( $\kappa=0.14$ vs. 0.35 , respectively). Both the OSS and Schirmer's test showed poor agreement with anti-SSA/SSB positivity ( $\kappa=0.21$ and $\kappa=0.27$ respectively).

\section{Discussion}

In this study, agreement was only moderate between the AECG and ACR criteria sets. The AECG criteria set classified more patients as having SS, whereas the ACR criteria set seemed to classify patients earlier in the course of the disease but included patients who did not have SS in the opinion of the physician. These discrepancies were chiefly ascribable to the absence in the ACR set of functional salivary gland testing (such as salivary flow measurement) and, above all, to the intrinsic differences between the OSS and Schirmer's test.

These two ocular dryness tests had very low agreement. According to the latent class analysis method used to develop the ACR classification criteria [2], the OSS had $89.7 \%$ sensitivity but only $37.8 \%$ specificity for SS, whereas Schirmer's test had a lower sensitivity of $42.7 \%$ but a better specificity of $75.1 \%$. In our study, in patients fulfilling neither criteria set (and who were therefore unlikely to be diagnosed with SS), an abnormal OSS was more common than an abnormal Schirmer's test, suggesting lower specificity of the OSS. To compare the diagnostic usefulness of these two tests, we did not use the physician's diagnosis as the reference, since this diagnosis relied chiefly on Schirmer's test and not on the OSS. Instead, we evaluated the agreement of the ocular dryness tests with the focus score and anti-SSA/SSB positivity, two major diagnostic features of SS [6] that served as external validation criteria. Compared with the OSS, Schirmer's test showed slightly better agreement with the focus score.

In the recently published study by Rasmussen and colleagues, the discordance between AECG and ACR criteria was also mostly attributed to the differences between the tests assessing the objective ocular component [7]. In their study, OSS displayed a poor specificity for SS ( 45 to $51 \%$ ), which could be partially corrected by increasing its positivity cutoff value from $\geq 3$ to $\geq 4 / 12$.

A complete ophthalmological evaluation is mandatory in patients with suspected SS, in particular to assess eyelid diseases and the differential diagnoses of keratoconjunctivitis sicca. However, classification tools should rely on the most specific items. Advantages of Schirmer's test include ease of use, even at the bedside in any clinical ward where trained staff members are available, and good performance as a screening tool for SS [8].

The serological item of the AECG criteria could probably be improved, since roughly $40 \%$ of primary SS patients do not have anti-SSA/SSB antibodies. However, we have shown here that the adjunction of ANA and RF, as proposed in the ACR criteria, did not modify the classification potential of anti-SSA/SSB alone. Other tests should be evaluated when new classification criteria will be developed, such as blood B-cell phenotyping [9] or other autoantibodies [10].

Another intrinsic difference between the AECG criteria and the ACR criteria is the absence of items assessing the subjective component of the disease in the latter. Indeed, the ACR criteria do not target the general population but only patients with suspected SS, who complain most of the time of sicca symptoms as in our study. Conversely, the AECG criteria may be applied to any patient thanks to the inclusion of the symptoms in items 1 and 2 (see Table 1). However, the preliminary European criteria and then the AECG criteria were not designed to be used in the general population, since the control patients enrolled in their development study 'were to be selected from those subjects referred to an SS expert because of ocular or oral signs and symptoms that simulated the clinical manifestations of SS, and for whom a complete evaluation was justified in order to establish a differential diagnosis' [11]. The precise diagnostic value of several questionnaires assessing ocular and oral symptoms has been carefully evaluated in these patients with suspected SS [12]. Such questionnaires may be valid tools for SS screening in the general population [8], but in our study the subjective symptoms did not participate in the discrepancy between AECG and ACR criteria, since nearly all patients had sicca complaints.

An earlier study compared the AECG criteria, the ACR criteria and the Japanese classification criteria sets 
for SS [13]. Taking the physician's diagnosis as the reference standard, the AECG and ACR criteria sets had $78.6 \%$ and $77.5 \%$ sensitivity, respectively, and $90.4 \%$ and $83.5 \%$ specificity.

However, a direct comparison of the AECG and ACR criteria sets in terms of sensitivity and specificity, taking the physician's diagnosis as the reference standard, may be inherently biased, as physicians probably rely heavily on the currently used AECG criteria set to diagnose SS. The resulting circular reasoning may overestimate the metrological features of the AECG criteria set.

Classification criteria for systemic diseases such as SS, rheumatoid arthritis, systemic lupus erythematosus, systemic sclerosis and inflammatory myopathies are designed to improve the homogeneity of populations enrolled in clinical studies, in order to allow valid comparisons across studies [14-17]. Since no specific reference standard is available for diagnosing these complex diseases, classification criteria are often used for diagnostic purposes, despite their limitations [18-20].

Whether classification criteria should have a higher sensitivity or specificity is a matter of debate. Foremost, classification criteria might be used to recruit patients in epidemiological studies; for example, to describe the whole spectrum of a disease including the mildest forms, and to define prognostic factors. For such a study, the classification criteria sensitivity should be high, even to the detriment of their specificity, since it would not be dangerous to include patients for whom the diagnosis is not definitely certain. Conversely, in therapeutic trials using potentially harmful drugs such as immunosuppressant or biological therapies, one could not take the risk of including patients who do not have the disease. In that case, the classification criteria have to be the most specific possible. All published classification criteria for SS, including preliminary European and AECG criteria, have a very high specificity (95 to $100 \%$ ) but variable sensitivity (60 to 95\%) [21]. The scientific community must achieve the widest consensus for a new classification system, which would display the best combination of sensitivity and specificity in order to be used universally in both epidemiological and therapeutic studies. To achieve this goal, a large international study is warranted, and the new classification criteria should include new diagnostic tools that were validated recently, such as salivary gland ultrasonography [4,22-24].

\section{Conclusions}

In this study, agreement was only moderate between the AECG and ACR criteria sets. This discrepancy was mainly ascribable to the intrinsic differences between the tests assessing the ocular component of the criteria. Our results suggest that the ACR criteria may detect early forms of disease affecting specific SS subpopulations such as those with negative anti-SSA/SSB autoantibodies. On the other hand, the AECG criteria seem definitely more specific but also more stringent. The existence of two different classification criteria sets for SS that select different patient populations may cause confusion [25,26]. An international study under the auspices of both the ACR and the European League Against Rheumatism is warranted to develop new universally recognized classification criteria, which would probably include new procedures such as major salivary gland ultrasonography.

\section{Abbreviations}

ACR: American College of Rheumatology; AECG: American-European Consensus Group; ANA: antinuclear antibody; OSS: ocular staining score; RF: rheumatoid factor; SS: Sjögren's syndrome.

\section{Competing interests}

The authors declare that they have no competing interests.

\section{Authors' contributions}

DC was responsible for conception and design, data collection, statistical analysis, manuscript writing and final approval of the manuscript. AS was responsible for conception and design, data collection, statistical analysis, critical revision and final approval of the manuscript. BC, J-OP, SJ-J, YR and TM were responsible for data collection and analysis, critical revision and final approval of the manuscript. VD-P was responsible for conception and design, data collection and analysis, manuscript writing and final approval of the manuscript. All authors read and approved the final manuscript.

\section{Acknowledgments}

Written informed consent was obtained from the patients for publication of this manuscript and accompanying clinical data in Table 3.

\section{Author details}

'CedexService de Rhumatologie, CHRU Brest, Hôpital de la Cavale Blanche, Boulevard Tanguy Prigent, 29609 Brest Cedex, France. ²EA 2216 Immunologie et Pathologie, SFR ScinBios, Labex 'Immunotherapy, Graft, Oncology', Faculté de médecine de Brest, avenue Camille Desmoulins, 29200 Brest, France. ${ }^{3}$ Service d'Ophtalmologie, CHRU Brest, Hôpital Morvan, Avenue Foch, 29609 Brest Cedex, France. ${ }^{4}$ Service d'Odontologie, CHRU Brest, Hôpital Morvan, Avenue Foch, 29609 Brest Cedex, France. ${ }^{5}$ Laboratoire d'Immunologie, CHRU Brest, Hôpital Morvan, Avenue Foch, 29609 Brest Cedex, France. ${ }^{6}$ Service de Rhumatologie, Hôpital de la Cavale Blanche, BP 824, F 29609 Brest Cedex, France.

Received: 19 September 2013 Accepted: 4 March 2014

Published: 19 March 2014

\section{References}

1. Vitali C, Bombardieri S, Jonsson R, Moutsopoulos HM, Alexander EL, Carsons SE, Daniels TE, Fox PC, Fox Rl, Kassan S: Classification criteria for Sjögren's syndrome: a revised version of the European criteria proposed by the American-European Consensus Group. Ann Rheum Dis 2002, 61:554-558.

2. Shiboski SC, Shiboski CH, Criswell LA, Baer AN, Challacombe S, Lanfranchi H, Schiødt M, Umehara H, Vivino F, Zhao $Y$, Dong $Y$, Greenspan D, Heidenreich AM, Helin P, Kirkham B, Kitagawa K, Larkin G, Li M, Lietman T, Lindegaard J, McNamara N, Sack K, Shirlaw P, Sugai S, Vollenweider C, Whitcher J, Wu A, Zhang S, Zhang W, Greenspan JS, et al: American College of Rheumatology classification criteria for Sjögren's syndrome: a data-driven, expert consensus approach in the Sjögren's International Collaborative Clinical Alliance Cohort. Arthritis Care Res 2012, 64:475-487.

3. Whitcher JP, Shiboski CH, Shiboski SC, Heidenreich AM, Kitagawa K, Zhang S, Hamann S, Larkin G, McNamara NA, Greenspan JS, Daniels TE, Sjögren's International Collaborative Clinical Alliance Research Groups: A simplified quantitative method for assessing keratoconjunctivitis sicca from the Sjögren's Syndrome International Registry. Am J Ophthalmol 2010, 149:405-415. 
4. Cornec D, Jousse-Joulin S, Pers J-O, Marhadour T, Cochener B, Boisramé-Gastrin S, Nowak E, Youinou P, Saraux A, Devauchelle-Pensec V: Contribution of salivary gland ultrasonography to the diagnosis of Sjögren's syndrome: toward new diagnostic criteria? Arthritis Rheum 2013, 65:216-225.

5. Chisholm DM, Mason DK: Labial salivary gland biopsy in Sjögren's disease. J Clin Pathol 1968, 21:656-660.

6. Guellec D, Cornec D, Jousse-Joulin S, Marhadour T, Marcorelles P, Pers J-O, Saraux A, Devauchelle-Pensec V: Diagnostic value of labial minor salivary gland biopsy for Sjögren's syndrome: a systematic review. Autoimmun Rev 2013, 12:416-420.

7. Rasmussen A, Ice JA, Li H, Grundahl K, Kelly JA, Radfar L, Stone DU, Hefner KS, Anaya J-M, Rohrer M, Gopalakrishnan R, Houston GD, Lewis DM, Chodosh J, Harley JB, Hughes P, Maier-Moore JS, Montgomery CG, Rhodus $N L$, Farris AD, Segal BM, Jonsson R, Lessard CJ, Scofield RH, Sivils KLM: Comparison of the American-European Consensus Group Sjogren's syndrome classification criteria to newly proposed American College of Rheumatology criteria in a large, carefully characterised sicca cohort. Ann Rheum Dis 2014, 73:31-38.

8. Sánchez-Guerrero J, Pérez-Dosal MR, Celis-Aguilar E, Cárdenas-Velázquez F, Soto-Rojas AE, Avila-Casado C: Validity of screening tests for Sjögren's syndrome in ambulatory patients with chronic diseases. J Rheumatol 2006, 33:907-911.

9. Cornec D, Saraux A, Pers J-O, Jousse-Joulin S, Marhadour T, RoguedasContios A-M, Genestet S, Renaudineau Y, Devauchelle-Pensec V: Diagnostic accuracy of blood B-cell subset profiling and autoimmunity markers in Sjogren's syndrome. Arthritis Res Ther 2014, 16:R15.

10. Bournia V-K, Vlachoyiannopoulos PG: Subgroups of Sjögren syndrome patients according to serological profiles. J Autoimmun 2012, 39:15-26.

11. Vitali C, Bombardieri S, Moutsopoulos HM, Balestrieri G, Bencivelli W, Bernstein RM, Bjerrum KB, Braga S, Coll J, de Vita S: Preliminary criteria for the classification of Sjögren's syndrome. Results of a prospective concerted action supported by the European Community. Arthritis Rheum 1993, 36:340-347.

12. Vitali C, Moutsopoulos HM, Bombardieri S: The European Community Study Group on diagnostic criteria for Sjögren's syndrome. Sensitivity and specificity of tests for ocular and oral involvement in Sjögren's syndrome. Ann Rheum Dis 1994, 53:637-647.

13. Tsuboi $H$, Hagiwara $S$, Asashima $H$, Umehara H, Kawakami A, Nakamura $H$, Sano H, Tsubota K, Ogawa Y, Takamura E, Saito I, Inoue H, Nakamura S, Moriyama M, Takeuchi T, Tanaka Y, Hirata S, Mimori T, Matsumoto I, Sumida T: Validation of different sets of criteria for the diagnosis of Sjögren's syndrome in Japanese patients. Mod Rheumatol Jpn Rheum Assoc 2013, 23:219-225.

14. Aletaha D, Neogi T, Silman AJ, Funovits J, Felson DT, Bingham CO 3rd, Birnbaum NS, Burmester GR, Bykerk VP, Cohen MD, Combe B, Costenbader KH, Dougados M, Emery P, Ferraccioli G, Hazes JMW, Hobbs K, Huizinga TWJ, Kavanaugh A, Kay J, Kvien TK, Laing T, Mease P, Ménard HA, Moreland LW, Naden RL, Pincus T, Smolen JS, Stanislawska-Biernat E, Symmons D, et al: 2010 rheumatoid arthritis classification criteria: an American College of Rheumatology/European League Against Rheumatism collaborative initiative. Ann Rheum Dis 2010, 69:1580-1588.

15. Petri M, Orbai A-M, Alarcón GS, Gordon C, Merrill JT, Fortin PR, Bruce IN, Isenberg D, Wallace DJ, Nived O, Sturfelt G, Ramsey-Goldman R, Bae S-C, Hanly JG, Sánchez-Guerrero J, Clarke A, Aranow C, Manzi S, Urowitz M, Gladman D, Kalunian K, Costner M, Werth VP, Zoma A, Bernatsky S, Ruiz-Irastorza G, Khamashta MA, Jacobsen S, Buyon JP, Maddison P, et al: Derivation and validation of the Systemic Lupus International Collaborating Clinics classification criteria for systemic lupus erythematosus. Arthritis Rheum 2012, 64:2677-2686.

16. Troyanov Y, Targoff IN, Tremblay J-L, Goulet J-R, Raymond Y, Senécal J-L: Novel classification of idiopathic inflammatory myopathies based on overlap syndrome features and autoantibodies: analysis of 100 French Canadian patients. Medicine (Baltimore) 2005, 84:231-249.

17. van den Hoogen F, Khanna D, Fransen J, Johnson SR, Baron M, Tyndall A, Matucci-Cerinic M, Naden RP, Medsger TA, Carreira PE, Riemekasten G, Clements PJ, Denton CP, Distler O, Allanore Y, Furst DE, Gabrielli A, Mayes MD, van Laar JM, Seibold JR, Czirjak L, Steen VD, Inanc M, Kowal-Bielecka O, Müller-Ladner U, Valentini G, Veale DJ, Vonk MC, Walker UA, Chung L, et al: 2013 classification criteria for systemic sclerosis: an American college of rheumatology/European league against rheumatism collaborative initiative. Ann Rheum Dis 2013, 72:1747-1755.
18. Radner H, Neogi T, Smolen JS, Aletaha D: Performance of the 2010 ACR/ EULAR classification criteria for rheumatoid arthritis: a systematic literature review. Ann Rheum Dis 2014, 73:114-123.

19. Van der Helm-van Mil AHM, Huizinga TWJ: The ACR/EULAR criteria for rheumatoid arthritis: do they affect the classification or diagnosis of rheumatoid arthritis? Ann Rheum Dis 2012, 2010:1596-1598.

20. Baldini C, Talarico R, Tzioufas AG, Bombardieri S: Classification criteria for Sjogren's syndrome: a critical review. J Autoimmun 2012, 39:9-14.

21. Vitali C, Bombardieri S, Moutsopoulos HM, Coll J, Gerli R, Hatron PY, Kater L, Konttinen YT, Manthorpe R, Meyer O, Mosca M, Ostuni P, Pellerito RA, Pennec Y, Porter SR, Richards A, Sauvezie B, Schiødt M, Sciuto M, Shoenfeld Y, Skopouli FN, Smolen JS, Soromenho F, Tishler M, Wattiaux MJ: Assessment of the European classification criteria for Sjögren's syndrome in a series of clinically defined cases: results of a prospective multicentre study. The European Study Group on Diagnostic Criteria for Sjögren's Syndrome. Ann Rheum Dis 1996, 55:116-121.

22. Bootsma H, Spijkervet FKL, Kroese FGM, Vissink A: Toward new classification criteria for Sjögren's syndrome? Arthritis Rheum 2013, 65:21-23.

23. Vitali C, Carotti M, Salaffi F: Is It the time to adopt salivary gland ultrasonography as an alternative diagnostic tool for the classification of patients with Sjögren's syndrome? Comment on the article by Cornec et al. Arthritis Rheum 1950, 2013:65.

24. Cornec D, Jousse-Joulin S, Saraux A, Devauchelle-Pensec V: Reply. Arthritis Rheum 1951, 2013:65.

25. Vitali C, Bootsma H, Bowman SJ, Dorner T, Gottenberg J-E, Mariette X, Ramos-Casals M, Ravaud P, Seror R, Theander E, Tzioufas AG: Classification criteria for Sjogren's syndrome: we actually need to definitively resolve the long debate on the issue. Ann Rheum Dis 2013, 72:476-478.

26. Bowman SJ, Fox RI: Classification criteria for Sjogren's syndrome: nothing ever stands still! Ann Rheum Dis 2014, 73:1-2.

\section{doi:10.1186/ar4514}

Cite this article as: Cornec et al:: Level of agreement between 2002 American-European Consensus Group and 2012 American College of Rheumatology classification criteria for Sjögren's syndrome and reasons for discrepancies. Arthritis Research \& Therapy 2014 16:R74.

\section{Submit your next manuscript to BioMed Central and take full advantage of:}

- Convenient online submission

- Thorough peer review

- No space constraints or color figure charges

- Immediate publication on acceptance

- Inclusion in PubMed, CAS, Scopus and Google Scholar

- Research which is freely available for redistribution 